\title{
Основные вызовы и угрозы национальной безопасности: польская перспектива
}

\author{
Анджей Глен ${ }^{*}$
}

\section{Введение}

В начале двадцать первого века угрозы безопасности Польши были существенно пересмотрены, и они продолжают изменяться. На текущий момент маловероятна угроза появления конфликта, который мог бы привести к войне глобального масштаба. Однако появились новые источники потенциального конфликта, которые могут стать серьезными вызовами и представлять обширную угрозу национальной безопасности Польши. Чтобы встретить эти вызовы и эффективно нейтрализовать проистекающие из них угрозы системе национальной безопасности, польскому руководству необходимо определить, какие из угроз по своему характеру являются наиболее фундаментальными и какие имеют второстепенное значение.

Целью этой статьи является выяснение текущих вызовов и угроз национальной безопасности Польской республики и оказание помощи в создании осведомленности об уже существующих проблемах и угрозах. Может быть, некоторые выводы, сделанные в этой статье, будут полезны лицам, принимающим решения и отвечающим за безопасность Польши. Процесс объяснения напряженности, которую представляют эти угрозы для национальной безопасности, лучше всего начинать формулировкой системы вопросов, относящихся к каждому из потенциальных конфликтов: Какую угрозу представляет он для безопасности Польской республики? Как эти угрозы могут проявиться? И почему конкретный конфликт является предметом озабоченности?

В этой статье делается попытка преодолеть трудности, проистекающие от применения телеологического подхода, начиная с проблемы и формулируя рабочую гипотезу, которая в наибольшей степени отражает сущность текущих вызовов и угроз польской национальной безопасности. Применение этого метода стало возможным благодаря тщательному подбору системы семантических понятий, на которых основывается это исследование и затем интерпретированию разных типов вызовов и угроз.

Решение проблемы и верификация рабочих гипотез требует применения как дедуктивного, так и индуктивного метода исследования. Интерпретация базовых концепций проводится в основном путем анализа словообразования, индуктивными и филологическими рассуждениями, дедуктивным выводом, которые обеспечивают получение новых научный фактов и делают возможным создание необ-

Др. Анджей Глен является доцентом факультета национальной безопасности польского Национального университета обороны в Варшаве. Также занимает должность заместителя ректора по научным исследованиям. Область его специализации включает методологию национальной безопасности, менеджмент кризисов и авиационную безопасность. 
ходимых определений. Однако система рисков была сконструирована, следуя принципам формальной логики и правилам дихотомического деления в Платоновой форме (как противоположные характеристики). Описание характеристик разных типов угроз было сделано путем анализа множества примеров, наличествующих в литературе, путем проведения вербальных тестов этих моделей угроз и синтезом каузального анализа полученных результатов. И последнее, при формулировании окончательных выводов я опирался на неполную перечислительную индукцию (каноны Милля) и на дедуктивные рассуждения.

\section{Основные понятия}

Получение сравнительно упорядоченных ответов на вопросы: Что угрожает Польской республике? Как и почему?, требует метода кларификации, который адаптирован к потребностям выработки способа понимания системы элементарных понятий. Без такой кларификации основных понятий, которые будут использоваться, описание угроз национальной безопасности практически невозможно. Эти концепции будут рассмотрены ниже.

Дилеммы государства, касающиеся вопросов безопасности, в литературе обычно называются вызовами национальной безопасности. ${ }^{1}$ Эти вызовы можно принять или пренебречь ими, и любое из этих решений может создать как дополнительные возможности, так и дополнительные угрозы. Такое понимание вызовов национальной безопасности следует считать разумным при условии, что само понятие вызова определено более точно. ${ }^{2}$ «Вызовом» (с небольшой модификацией подхода к категории национальная безопасность, как предложено М. Цесларжиком $^{3}$ ) считается ситуация (или информация о ситуации), которая если не будет обнаружена вовремя и если для нее не будет найдена и выполнена в правильном месте и в правильное время тщательно отобранная последовательность действий с привлечением соответствующих способностей, может превратится в «угрозу». И наоборот, она может стать возможностью, которую можно понимать как таковую в зависимости от обстоятельств, имеющих значение для интересов и целей государства.

В свою очередь, угрозы государственной безопасности часто понимаются в терминах потенциально деструктивного влияния на страну и воплощаются в форме «кризисов» или «конфликтов». В глоссарии уже цитированных терминов угрозы понимаются как «ситуация», тогда как разные виды угроз характеризуются

1 Смотри: Stownik terminów z zakresu bezpieczeństwa narodowego (Словарь терминов национальной безопасности) (Warsaw: AON, 2002).

2 Далее в этой статье национальная безопасность понимается как безопасность демократического государства, следовательно, как безопасность Польской республики.

3 Marian Cieślarczyk, Teoretyczne i metodologiczne podstawy badania problemów bezpieczeństwa i obronności państwa (Теоретические и методологические основы исследований проблем государственной безопасности и обороны) (Siedlce: Wydawnictwo Akademii Podlaskiej, 2009). 
как «производные глобализации», «комбинация обстоятельств» и т.д. В этом случае для потребностей польской национальной безопасности оказывается подходящим понимать угрозы как сбор событий, имеющий место в и/или вне государства, который может привести к невозможности обеспечить следующее:

- Сохранение территориальной целостности, идентичности и суверенной власти страны

- Выживание нации

- Поддержание внутреннего порядка и главенства закона

- Условия, необходимые для гарантирования качества жизни и национального развития. ${ }^{4}$

Однако под термином угроза, в общем понимают событие, которое вызвано непредсказуемыми или непреднамеренными событиями, имеющими отрицательное влияние на функционирование системы или вызывающими неблагоприятные (опасные) изменения в ее структуре или функционировании. ${ }^{5}$ Если оставить угрозы без внимания, их аккумуляция может привести к кризисной ситуации как в самой системе, так и в ее окружении.

«Безопасность» в узком смысле в широких кругах понимается как ощущение отсутствия риска. Эта тесная связь угроз с понятием безопасности приводит к прояснению того, как национальная безопасность может быть понята в контексте какой-нибудь угрозы. В теории, понимание функций национальной безопасности включает такие факторы как ценности, потребности, статус, процесс и цели. ${ }^{6}$ Такое толкование национальной безопасности позволяет нам лучше понять ее сущность; однако, этот подход также содержит существенные логические ошибки.

Наиболее важная из них - это non-definito fit per genus et differentia sepecifica. Одно возможное решение проблемы нахождения определения понятия национальной безопасности состоит в классификации категории уверенности в контексте безопасности. Однако, кларификация различий такого вида может быть достигнута путем вычисления наиболее существенных ценностей безопасности. Пьотр Сенкевич привлекает наше внимание к таким атрибутам безопасности как существование, выживание, целостность, идентичность, независимость, право

4 Stanisław Dworecki, Zagrożenia bezpieczeństwa państwa (Угрозы безопасности государства) (Warsaw: AON, 1994), 61.

5 Kryzsztov Ficoń, Inżynieria zarządania kryzysowego (Инженеринг кризисного менеджмента) (Warsaw: Bel Studio Sp, z o.o., 2007), 76.

6 Jerzy Stańczyk, Wspótczesne pojmowanie bezpieczeństwa (Современное понимание безопасности) (Warsaw: Instytut Studiów Politycznych PAN, 1996), 15-19; Waldemar Kitler, "Bezpieczeństwo narodowe" (Национальная безопасность) TWO, Zeszyt problemowy 1:61 (2010). 
собственности и гарантированность развития. ${ }^{7}$ Этот автор перечисляет следующие ценности национальной безопасности:

- Выживание государства как политической организации, нации как конкретной этнической группы и биологическое выживание населения

- Территориальная целостность

- Политическая независимость (уровень политической свободы, например, в случае нации без собственного государства)

- Качество жизни, которое может быть оценено количественно по стандарту жизни, уровню социально-экономического развития, правам и свободам, «национальному стилю жизни»

- Окружающая среда, развитие и другие. ${ }^{8}$

В свою очередь, Вальдемар Китлер приводит такие ценности национальной безопасности как выживание нации, идентичность страны, внутренний порядок, главенство закона, высокий международный престиж, моральная и материальная мощь. ${ }^{9}$ Поэтому будет оправданно понимать национальную безопасность как уверенность быть в состоянии сохранять территориальную целостность и политическую независимость, правовую систему, высокий международный престиж, духовную и материальную мощь государства, обеспечивая в то же время национальную идентичность, человеческие и гражданские права, жизнь и здоровье, культуру и обычаи, свободу, высокое качество жизни, развитие личности и социальных групп.

\section{Характеристики угроз национальной безопасности}

Понимание смысла категорий «вызов, угроза, возможности и национальная безопасность» позволяет нам предпринять попытку систематизировать угрозы национальной безопасности. Нахождение единого критерия, который подходил бы к множеству уровней угроз безопасности разным элементам государства, было нелегко, но оказалось возможным. Хотя в литературе и встречается мнение, что «динамика идентифицированных угроз сегодня не позволяет создание перманентной классификации», не следует поддаваться таким предположениям. ${ }^{10}$ Они относятся к конкретным типам классификаций (например, переменных характеристик), выполняемым в соответствии с объективными критериями. Такие классификации органически трудно закончить и без включения позиции «другие угрозы», отлич-

7 Piotr Sienkiewicz, “Analiza systemowa polityki bezpieczeństwa państwa” (Системный анализ политики безопасности государства), Zeszyty Naukowe (NDU Scientific Qaurterly) 4 (2005): 34.

8 Там же, 35.

9 Kitler, "Bezpieczeństwo narodowe," 22.

10 Sławomir Zalewski, Bezpieczeństwo polityczne państwa (Политическая безопасность государства) (Siedlce: Wydaw. Akademii Podlaskiej, 2010), 199. 


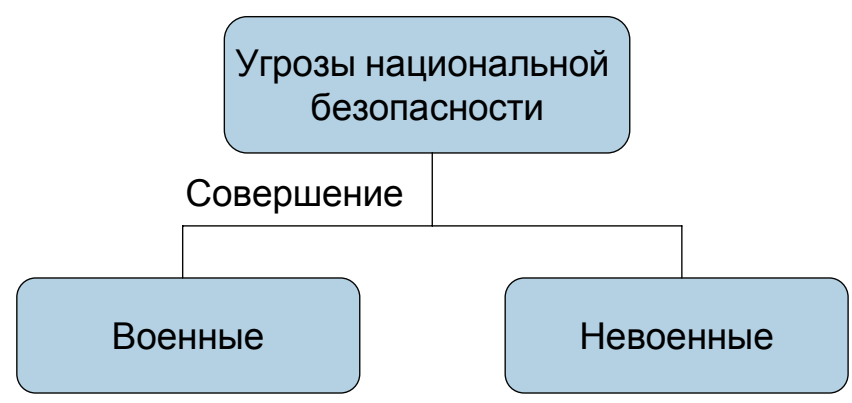

Фигура 1: Диаграмма вызовов и угроз государственной безопасности (уровень 1).

ные от тех, которые уже были идентифицированы, и которые никогда не будут закончены. Относительную нестабильность такой классификации следует считать не недостатком, а скорее атрибутом классификации, обусловленным переменными характеристиками. Независимо от всего этого, надо принять, что многочисленные и различные угрозы национальной безопасности, идентифицированные в литературе по национальной безопасности, варьируют по охвату и содержанию в зависимости от целевой функции классификации.

Обозначенная проблематическая природа определенных классификаций угроз национальной безопасности стала причиной поиска решений проблемы системных рисков в области дихотомических классификаций на основе противоречащих характеристик. Однако, поиск критерия разделения имел место и сам критерий был найден путем «соотнесения безопасности с четырьмя причинами настоящего знания (которые различает Аристотель - causa materialis, causa formalis, causa efficiens (совершения, А.Г.), causa finalis) и ее идентификации с формами существования». ${ }^{11}$ Среди аристотелевских причин, причина совершения была принята в качестве удобного критерия для многоуровневого дихотомического деления угроз национальной безопасности.

В то время, когда выбирался тип схемы для классификации угроз и критерий для их деления, обнаружились два факта. Первый - это то, что в словарях и энциклопедиях часто считается рациональным разделять источники угроз на природные и созданные человеком. Второй факт описывает ситуацию, связанную с восприятием влияния исчезновения двухполюсного деления мира. До конца Холодной войны национальная безопасность воспринималась в основном в терминах военных угроз, тогда как после падения Железного занавеса дефиниция национальной безопасности постепенно приняла характер «двуликого Януса» и воспринимается как в терминах военных, так и в терминах невоенных угроз одновременно. Следовательно, было бы оправдано, в особенности в случае национальной безопасности, на первом уровне разделить их на военные и невоенные.

11 Jörg Disse, Metafizyka od Platona do Hegla (Метафизика от Платона до Гегеля) (Kraków: Wydawnictwo WAM, 2005), 70. 


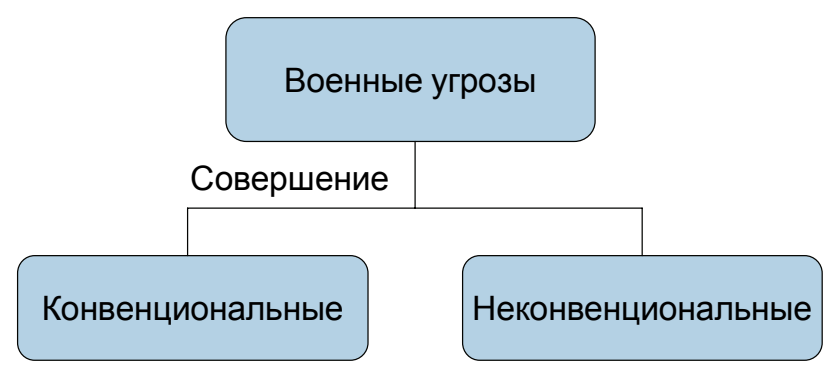

Фигура 2: Диаграмма угроз национальной безопасности (военные угрозы, уровень 2).

Военные угрозы включают те, чьим источником являются вооруженные силы другого государства как субъекта международного права, коалиции или альянса таких государств. Невоенными угрозами, с другой стороны, следует считать все те, чьей причиной являются отдельные люди, социальные группы или организации, которые не используют вооруженные силы государства.

Военные угрозы могут иметь конвенциональный характер, если враг использует сухопутные, военно-воздушные, военно-морские и специальные силы, и он вооружен конвенциональным оружием ограниченной дальности. Неконвенциональные угрозы ассоциируются с оружием массового уничтожения (ОМУ), а также и с новыми технологиями со сравнимой или даже большей дальности действия или разрушительной силы, чем оружия массового уничтожения, такими как психотропное оружие, которое в состоянии влиять на настроение и состояние умов целых наций. Возможность бесконтрольного распространения оружия массового уничтожения и средств его доставки составляет одну из основных транснациональных угроз безопасности. Материалы и технологии, которые можно использовать для создания таких оружий их носителей, становятся все более доступными. Однако инструменты и сама процедура для обнаружения и предотвращения незаконной торговли такими материалами и технологиями остаются неэффективными или слишком сложными. Незаконный трафик компонентов для производства оружия массового уничтожения порождает угрозу их проникновения в недемократические страны, а так же в те страны, которые находятся под влиянием внутреннего конфликта или в состоянии конфликта с другими государствами. Такие материалы могут перейти в руки террористов или экстремистских групп. Польша находится в соседстве с территорией увеличенного риска распространения оружия массового уничтожения. В экстремальных случаях распространение ОМУ может стать прямой угрозой для нашей территории.

Границы дальнодействия военных угроз во времени и пространстве могут быть связаны с их способностью подвергать воздействию малую область (ограниченные в пространстве), или с их способностью воздействовать на всю национальную территорию в течение короткого времени (две или три недели) или на более долгий период, измеряемый годами. Однако неконвенциональные военные угрозы, 


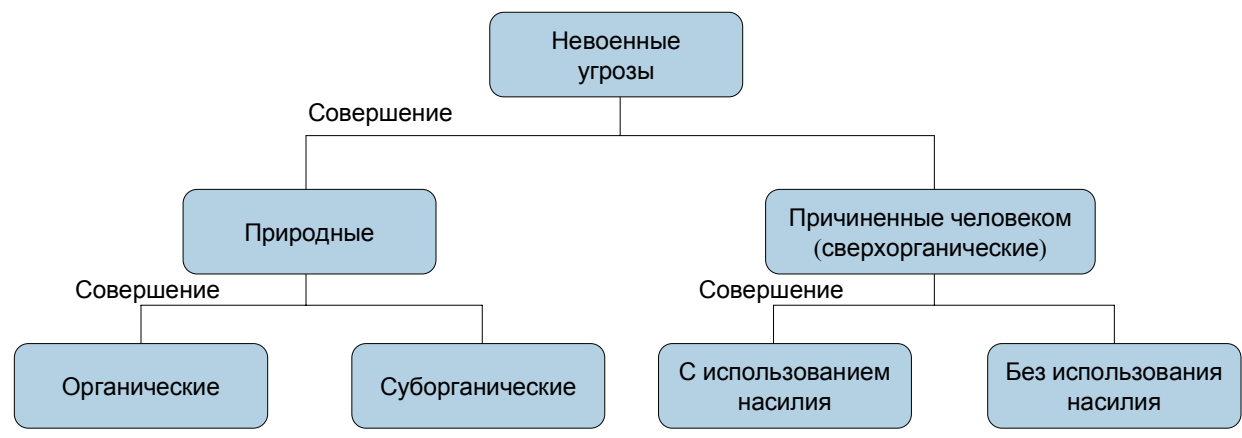

Фигура 3: Диаграмма угроз национальной безопасности (невоенные угрозы, уровни 2 и 3 ).

как правило, имеют более долгосрочное воздействие и большее пространственное дальнодействие (т.е. они в состоянии подвергать воздействию всю страну).

Уместно разделить невоенные угрозы национальной безопасности на такие, которые имеют неорганическую или суборганическую природу, и на такие, чьим источником является человек (который может использовать или не использовать насилие). В этой схеме отдельная личность считается членом социальной группы или организации; таким образом, суперорганическая часть нашей реальности - это сфера организаций, чьей высшей формой является государство. ${ }^{12}$

Органические угрозы национальной безопасности имеют биологические причины (исключающие человеческую деятельность). Такие угрозы имеют в основном биологический или эпидемиологический характер и основываются на переносе заразных болезней (вирусных или бактериальных) животными (например, мигрирующими птицами). Такие феномены могут стать причиной эпидемий или даже пандемий, которые могут угрожать безопасности отдельных наций и, в случае пандемий, населению всего мира. Примером таких пандемий являются периодически повторяющиеся в истории человечества пандемии гриппа, которые показаны ниже на фиг. 4.

Суборганические угрозы являются результатом действия неживых естественных сил, таких как бури и землетрясения, и для Польши могут оказаться более опасными, чем органические. Фикон различает три отдельные когерентные группы риска: космические, климатические и тектонические. ${ }^{13}$ Угрозы, идущие из Космоса, включают космическое и солнечное излучение, столкновения космиче-

12 Деление реальности на суборганическую, органическую и суперорганическую было предложено Лешем Янушом Кржижановским. Lech Janusz Krzyżanowski, O podstawach kierowania organizacjami inaczej: paradygmaty, filozofia, dylematy (Дифференциация на основе менеджмента организаций: парадигмы, философии, дилеммы) (Warsaw: PWN, 1999), 20.

13 Ficoń, Inżynieria zarzqdzania kryzysowego, 83. 


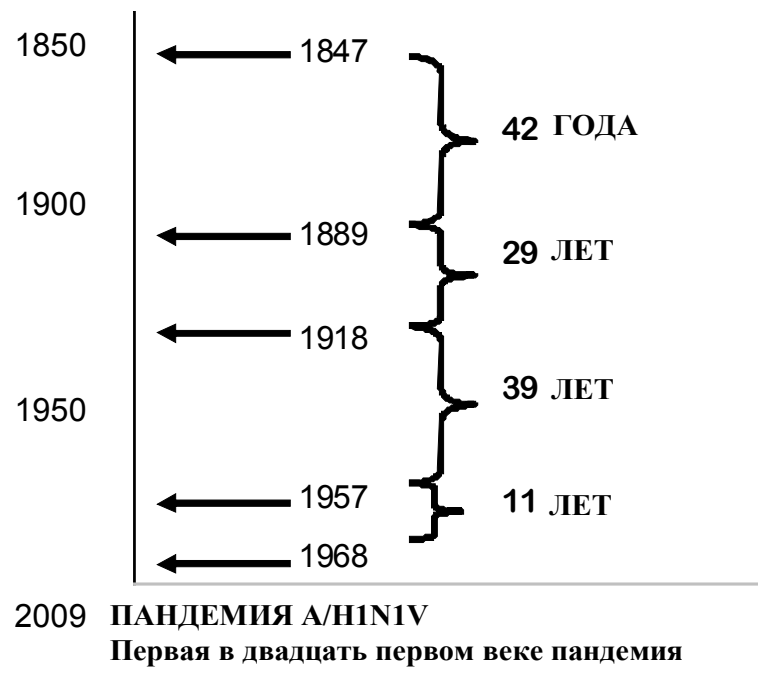

Фигура 4: Частота гриппных пандемий с 1847 года.

ских тел с Землей, изменения интенсивности земного магнетизма и встречи с внеземными цивилизациями. Наиболее часто встречающиеся категории климатических угроз - это наводнения, селевые потоки и оползни; засуха и жара; метели и снежные бури; сильные ветры (ураганы и смерчи); электрические бури; пожары, возникшие по природным причинам; и глобальное потепление.

И на последнем месте, тектонические опасности включают в основном землетрясения и извержения вулканов. Хотя Польша расположена в зоне низкой сейсмической активности, недавнее вулканическое извержение в Исландии (в апреле 2010 года, которое привело к авиакатастрофе в Смоленске) показало народу Польши, какому большому риску неживая природа может подвергнуть страну (в конкретном случае, паралич транспортной системы).

В свою очередь, угрозы национальной безопасности, созданные человеком классифицированные как суперорганические угрозы, - могут быть четко и конкретно разделены на такие, в которых тот, от кого они исходят, является личностью, использующей насилие, и такие, в которых действия личности являются косвенной причиной угрозы. Под насилием понимается оказание физического или психологического воздействия на процесс мышления, на поведение и физическое состояние людей без их согласия.

Современные угрозы национальной безопасности связаны в основном с напряженностью и нестабильностью, причиненными международным терроризмом, который в предложенной схеме расположен в категории невоенных угроз, источником которых является отдельный человек, использующий насилие. В настоящий момент терроризм является наибольшей угрозой международной безопасности 


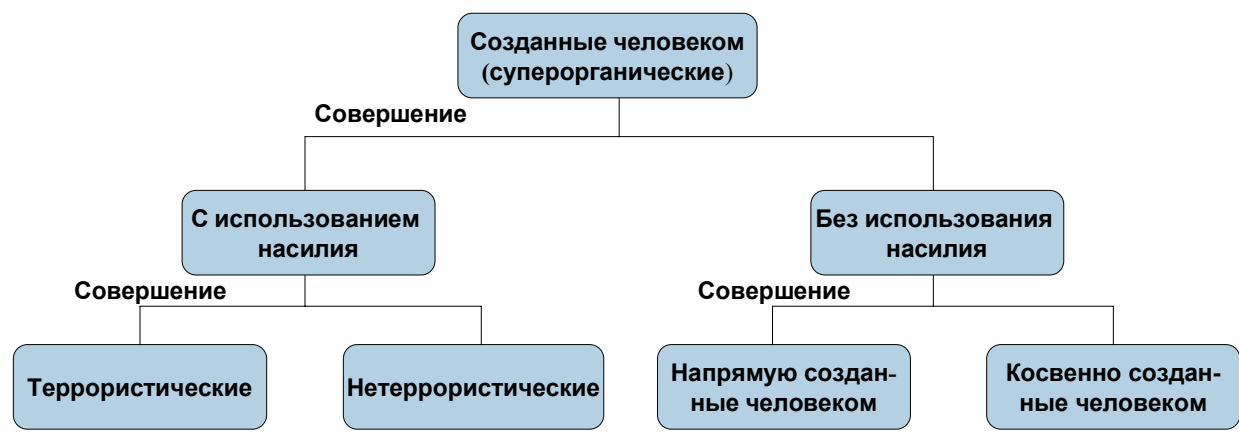

Фигура 5: Диаграмма угроз безопасности государства (невоенные угрозы, уровни 3 и 4).

(включая Польшу), хотя степень угрозы, порожденной терроризмом, различна для отдельных стран. ${ }^{14}$ Угроза международного терроризма приобрела совершенно новый характер, так как те, кто организует и совершает нападения, располагают средствами и методами, которые не вписываются в традиционные идеи терроризма. Акты терроризма направлены, среди прочих, против ценностей, институций и интересов большинства стран евроатлантического региона. Их действия подготавливаются с использованием современных средств коммуникации и с использованием преимуществ легкости передвижения в глобальной транспортной сети и осуществления международных банковских переводов. По своему характеру они беспощадны и рассчитаны на максимальное разрушительное воздействие на население. Примером проводимой подготовки террористических атак является нападение в Нью-Йорке в 2007 году, чьей целью был взрыв топливопроводов для заправки самолетов в аэропорту имени Кеннеди. Эти трубопроводы проходят под жилищами и многоквартирными домами. Если бы они были взорваны, последствия такого теракта трудно себе представить.

Быстроразвивающееся явление, которое подвергает опасности польские национальные интересы, это негосударственные риски, причиной которых являются не террористы, а трансграничная организованная преступность. Этот тип преступности связан с контрабандой оружия, опасных материалов, людей, наркотиков, с использованием таких методов как отмывание денег и коррупция. Потенциальная угроза состоит в потенциале массовой миграции отдельных людей или трансграничного транспорта материалов, которые могут стать угрозой для безопасности Польши. Центральное расположение Польши на европейском континенте увеличивает существующие риски в этой сфере, хотя вероятность массовой миграции

14 Jan Wojnarowski, Współczesne wyzwania i zagrożenia dla systemu bezpieczeństwa państwa w: Narodowy system pogotowia kryzysowego (Современные вызовы и угрозы системе безопасности государства и национальная система оповещения в кризисной ситуации) (Warsaw: AON, 2007), 12. 
такого типа на настоящий момент ограничена. Сейчас Польша должна учитывать экономические и социальные последствия миграционных процессов и нейтрализовать их отрицательные эффекты. В наши дни главным вызовом для государственных служб внутри Польши является существенный масштаб экономической миграции.

Территория Польши благодаря географическому расположению и относительной доступности может так же служить удобной логистической базой, где можно проводить подготовку и откуда возможно предпринимать действия против граждан, институций и компаний в других странах. Это включает вероятность того, что Польша может служить распределительным центром (а не просто коридором) для незаконного оборота наркотиков и торговли людьми. В последние годы в Польше наблюдается увеличение активности транснациональных криминальных групп, что привело к разнообразным социальным патологиям. Это серьезная угроза для Польши.

Но именно человеческие действия, напрямую или косвенным образом, являются наиболее серьезными угрозами для польской национальной безопасности (наряду с природными опасностями суборганического характера). Эти угрозы включают технические, социальные и экологические риски. Фикон делит технические риски на пожары, в том числе и природные, химические, строительные и транспортные аварии. ${ }^{15}$ Наиболее часто встречающаяся угроза, возникающая напрямую в результате человеческой небрежности или преднамеренных действий, или косвенно (из-за незнания правил, принципов противопожарной защиты или из-за отказов оборудования) - это пожар. Некоторые пожары имеют естественные причины, например, лесные пожары, которые часто случаются в результате молний, и поэтому включены в категорию суборганических, природных опасностей. Однако наиболее опасными пожарами в Польше являются промышленные и городские пожары, которые часто приводят к гибели или наносят вред здоровью большого числа людей. Более того, сочетание пожара и сгорания опасных промышленных субстанций часто связано с загрязнением окружающей среды на большом пространстве.

Химическое загрязнение является серьезной угрозой национальной безопасности. Токсичные промышленные вещества сопровождают развитие металлургической и автомобильной промышленности, производство каучука, удобрений, красок и лаков, как и многих других отраслей промышленности. Во время бедствий или аварий вещества такого сорта могут проникнуть в атмосферу, почву и грунтовые воды. В случае строительства в Польше атомных электростанций отказы в их системах могут представлять серьезную опасность. Возможное радиоактивное заражение может привести к значительной смертности среди людей и животных, а так же к многолетнему загрязнению окружающей среды, в частности земли и воды. Кроме того, хранение отработанных радиоактивных материалов, чья естест-

15 Ficoń, Inżynieria zarzadzania kryzysowego, 90. 
венная активность может длиться до 50000 лет, является существенной проблемой.

Другая категория угроз включает технические риски, связанные со строительными и транспортными авариями. Они могут происходить в жилищных зданиях и промышленных сооружениях, на объектах и средствах транспорта. Наиболее опасные последствия имеют аварии на больших гидросооружениях, таких как плотины и гидроэлектростанции. Катастрофы на общественных объектах, таких как большие арены, спортзалы и торговые центры, могут представлять большую опасность для человеческой жизни и здоровья. Кроме того, различные типы аварий в шахтах являются не только опасными, но часто связаны с человеческими жертвами.

Наиболее опасные для государства последствия имеют транспортные происшествия и катастрофы. Как было упомянуто выше, технические риски редко имеют серьезные последствия национального масштаба. Катастрофы на транспорте, такие как происшествия на дорогах, морские и авиационные катастрофы приводят к большому числу жертв; в Польше каждый год при таких происшествиях несколько тысяч человек погибают и десятки тысяч получают ранения. Происшествия на море и в воздухе приводят к трагедиям. Количество инцидентов и аварий такого вида невелико, но недавняя воздушная катастрофа самолета Ту-154 10 апреля 2010 года привела в Польше к гибели всех девяноста шести человек, находящихся на борту - девяноста шести наиболее важных личностей страны. Это событие заставило Польшу понять, как воздушная катастрофа может стать угрозой национальной безопасности в определенных обстоятельствах. Однако, определенно наибольшей угрозой - и с которой наиболее трудно справиться - являются происшествия на дорогах, которые случаются ежедневно и приводят к гибели нескольких тысяч людей каждый год.

Социальные риски являются другим множеством угроз для национальной безопасности, и их причиной является напрямую или косвенно человек как отдельная личность, или как член социальной группы или организации. Основные причины, лежащие в основе этих рисков, это обнищание общества, бедность, растущее неравенство между бедными и богатыми, гендерная дискриминация при поступлении на работу, безработица и растущий дисбаланс между количеством работающих и количеством пенсионеров. Кроме того, угрозы, проистекающие от компьютерных систем и сетей и часто встречающейся неосведомленности части потребителей таких систем и сетей о таких угрозах, как киберпреступления и кибертерроризм, тоже входят в категорию социальных угроз с очевидной тенденцией нарастания. Социальные последствия таких угроз оказывают влияние на ключевые акторы в системе национальной безопасности: на личности, социальные группы и организации, которые во все большей степени зависят от информационных технологий. В Польше эта опасность угрожает миллионам гражданам, а в глобальном масштабе риску подвергаются как минимум два миллиарда людей.

В дополнение, непрямая угроза национальной безопасности Польши проистекает от коллапса существующих государств, от нестабильности, порожденной 
«провалившимися» государствами, и от рисков, связанных с авторитарными и тоталитарными режимами, которые поддерживают эскалацию международного терроризма и обычно непредсказуемы в своих военных действиях (в том числе проявляя тенденцию к асимметричным действиям). В таких странах социальноэкономическая недоразвитость является причиной социального недовольства и экономической миграции. Некоторые из экономических мигрантов могут в конечном итоге приехать в Польшу из-за улучшающейся экономической ситуации в нашей стране. Можно предположить, что не все из них успеют социально адаптироваться к жизни в Польше и некоторые могут стать рисковыми факторами типов, упомянутых выше.

Энергетические угрозы, обусловленные разными причинами, включая недостаточную диверсификацию поставок энергоресурсов, в частности нефти и природного газа, также являются серьезной проблемой для безопасности Польши. Кроме того, ее безопасность может оказаться под угрозой из-за срыва мировой торговли и определенных действий со стороны наших соседей с Востока, связанных с принятием стандартов свободной торговли. Развитие информационных технологий и систем коммуникаций, связанных с рынками капитала, вызывает появление новых угроз, которые могут нарушить стабильность финансовой ситуации в Польше.

И последний, но не по значению фактор, это то, что экологические опасности являются очень важной категорией для национальной безопасности Республики Польша. В качестве основных групп причин таких угроз в литературе упоминаются демографические, географические, технические, экономические и социально-культурные опасности. ${ }^{16}$ Все эти источники, каждый по-своему, вызывают ухудшение состояния окружающей среды, в конечном итоге угрожая жизни, здоровью и общественному благосостоянию. Увеличивающееся число людей, проживающих в Польше, в том числе и те, которые мигрировали из авторитарных и тоталитарных государств, могут подорвать экологический баланс и способности инфраструктуры государства обеспечивать существование растущего населения. В свою очередь, географической разрыв между количеством природных ресурсов, необходимых для жизни человека, и реальными возможностями данной географической области, воспринимается как угроза экологической катастрофы. Такая ситуация приводит к увеличению загрязнения в процессе получения необходимых ресурсов. Экологические технические рисковые факторы возникают в основном от использования в Польше устаревших технологий, которые обычно производят значительное количество углекислого газа, загрязняющего атмосферу. Источники эколого-экономических рисков связаны с размещением на территории Польши таких видов производства, которые являются экологически обременительными для более развитых стран. Эти явления, наряду с отсутствием законодательных мер для регулирования эмиссий, загрязняющих окружающую среду в развивающихся странах, таких как Польша, снижают уровень экологической безопасности страны.

16 Там же, 107. 
Кроме того, экологические социально-культурные опасности, которые являются, главным образом, следствием факта того, что Польша развивается быстрыми темпами, но пока недостаточно инвестирует в охрану окружающей среды, могут превратиться в существенную угрозу. Наиболее опасными явлениями, снижающими экологическую безопасность, являются глобальное потепление, истощение озонового слоя, кислотные дожди и смог.

\section{Выводы}

Современная система национальной безопасности должна отвечать многим вызовам и угрозам в адрес государства. Наиболее важные вызовы и угрозы безопасности Польши, которые существуют в настоящее время, перечислены ниже. ${ }^{17}$

\section{Вызовы безопасности Польши}

1. Экономическая глобализация и регионализация, и проистекающее в результате этого свободное движения капиталов, товаров, информации и людей

2. Процессы демократизации в социально-политической и экономической cфepe

3. Международный терроризм

4. Неконтролируемое распространение оружия массового уничтожения и системы его доставки

5. Организованная преступность

6. Наличие «провалившихся» государств

7. Увеличение миграции населения

8. Компьютеризация всех сфер жизни

9. Обеспечение энергетической безопасности (в основном поставок нефти и природного газа)

10. Изменения климата, вызванные глобальным потеплением, связанным с загрязнением окружающей среды.

\section{Угрозы безопасности Польши}

1. Возможность террористических нападений

2. Организованная преступность - местная и международная мафия, которые часто борются за сферы влияния

3. Климатические изменения, которые приводят к экологическим катастрофам и сбоям в производстве сельскохозяйственной продукции

17 Wojnarowski, Współczesne wyzwania i zagrożenia dla systemu bezpieczeństwa państwa, 12, 13. 
4. Проблемы сырья, в том числе уменьшение наличия природных ресурсов (топлива и воды)

5. Социальные патологии (наркомания, похищение людей с целью выкупа, антиглобалистские движения, появление новых религиозных сект, снижение уровня культуры и т.д.)

6. Вспышки новых заболеваний (птичий грипп, сепсис, коровье бешенство, СПИД и т.д.)

7. Неокончательно установленное верховенство закона, недостаток политической культуры и нехватка навыков мирного урегулирования конфликтов

8. Сворачивание традиционных отраслей производства, приводящее к неблагоприятным изменениям в сфере занятости и росту безработицы

9. Претензии «перемещенных» немцев на получение компенсации

10. Асимметричные угрозы в Польше

11. Столкновения в сфере общественного мнения, которые могут привести к общественным разделениям, в том числе по таким спорным вопросам, как клерикализм и аборты, борьба между политическими партиями и кампании дезинформации со стороны части государственного управления

12. Кибератаки и информационные войны.

Современные вызовы и угрозы требуют углубления взаимозависимости национальных интересов в сфере безопасности разных стран, о чем свидетельствует тенденция отхода от национальных систем государственной безопасности к международным системам. В связи с динамикой и масштабами изменений в Европе и мире, польская система безопасности нуждается в адаптации к динамично меняющимся требованиям (условиям, стандартам, ожиданиям), сформулированным широким спектром субъектов в ее окружении. 